\title{
Experiences of social oppression among men who have sex with men in a cosmopolitan city in Nigeria
}

\author{
Adekemi O Sekoni' \\ Oluyemisi O Ayoola ${ }^{2}$ \\ Esther $\bigcirc$ Somefun ${ }^{3}$ \\ 'College of Medicine, University of \\ Lagos, ${ }^{2}$ Family Health International \\ Global HIV/AIDS Initiative, ${ }^{3}$ Nigerian \\ Institute of Medical Research, Yaba, \\ Lagos, Nigeria
}

This article was published in the following Dove Press journal:

HIVIAIDS - Research and Palliative Care

22 December 2014

Number of times this article has been viewed

Background: In several African countries, men who have sex with men (MSM) are becoming visible, as a result of which they are now victims of human rights violations. This has a negative effect on their ability to access services targeted at human immunodeficiency virus (HIV) prevention and care. The main objective of this study was to document the experiences of social oppression among MSM in Lagos State, Nigeria.

Methods: Simple random sampling was used to select three of the seven local government areas in Lagos State that had community centers. Snowball sampling was used to recruit 291 participants. The survey instrument was a pretested questionnaire. The results were presented as means and percentages. Univariate, bivariate, and multivariate analysis was carried out at $P<0.05$.

Results: The mean age of the participants was $25.3 \pm 4$.6 years, and the majority $(66.0 \%)$ were currently single and not in a steady relationship. Half of the men self-identified as gay and about $48 \%$ as bisexual. Alcohol use occurred in $56.7 \%$ of the respondents, about a quarter $(25.8 \%)$ smoked cigarettes, and $11.0 \%$ reported using hard drugs. The commonest acts of human rights violation and or violence reported were aggression $35.7 \%$, alienation $29.9 \%$, verbal abuse $19.2 \%$, physical abuse $17.9 \%$, rape by a man $16.8 \%$, and psychological abuse $20.3 \%$. The predictors of human rights violation were level of education (adjusted odds ratio 2.6, $P=0.019$ ), marital status (adjusted odds ratio 2.3, $P=0.005$ ), and sexual orientation (adjusted odds ratio 1.9, $P=0.017)$. For physical and sexual abuse, MSM who consumed alcohol and were homosexual/ transgender were at risk.

Conclusion: This study showed that a high proportion of MSM had experienced various forms of human rights violation and abuse as a result of their sexual orientation/identity. There is a need to document and quantify these happenings, which can serve as an advocacy tool for reform.

Keywords: social oppression, men who have sex with men, Lagos, Nigeria

\section{Introduction}

Social inequalities and exclusion make people vulnerable to ill health. People whose rights are not respected on the basis of their gender identity or sexual orientation lack protection within families and the community at large. This places a constraint on their ability to seek health services and information. At the same time, for economic reasons or due to low self-esteem, they may engage in risky behavior which can predispose them to infection with human immunodeficiency virus (HIV) and hepatitis virus. The lack of opportunities for people experiencing social exclusion pushes them toward financial poverty, worsens their physical and mental health status, and perpetuates this vicious cycle. ${ }^{1}$

According to research conducted by anthropologists, pockets of areas existed in Africa before the colonial era where homosexuality was practiced. It was the exception

Correspondence: Adekemi O Sekoni Department of Community Health and Primary Care, College of Medicine of the University of Lagos, Lagos University Teaching Hospital Compound, Idi Araba, Lagos, Nigeria

Tel 002348033448474

Email sekoniadekemi@yahoo.com 
rather than the rule. It was not openly acknowledged because issues related to sexuality were taboo and not intended for public discussion. ${ }^{2}$ Open acknowledgment of same sex relationships is perceived as a threat to the traditional African culture and religion because it contradicts their definition of what constitutes family and community. It does not conform to the societal norms governing male and female sexual behavior. It is also perceived to be the negative influence of westernization (globalization) and should therefore be repressed or curtailed. Several actions are undertaken to achieve this, including bullying, taunting, hostility, discrimination, and violence. ${ }^{3}$

Stigma, discrimination, and human rights violation has trailed the HIV epidemic and had posed a significant challenge hampering efforts geared toward prevention, care, and support. From the report of a survey conducted between 2008 and $2011,{ }^{4}$ a high proportion of men and women living with HIV in Nigeria reported verbal and physical abuse, experiencing stigma within the family and community, as well as loss of job or income..$^{5}$ Achieving universal access will remain a dream if people most at risk, infected, or affected cannot access information and services. This can be as a result of punitive laws, economic circumstances, religious beliefs, sociocultural prejudices, and norms that pose structural barriers. ${ }^{4}$

Human rights violations, including extrajudicial killings, torture, detention, and even rape, have been perpetuated against individuals on the basis of their sexual orientation and gender identity. To protect the human rights of individuals with respect to this issue, a set of guidelines, ie, the Yogyakarta principles, were developed to guide the application of international human rights. ${ }^{6}$

As of May 2013, most of the UN member countries were not conforming to the Yogyakarta principles; 65 countries and 85 entities have anti-discriminatory laws compared with the 31 countries and 35 entities that recognize same sex unions. Same sex activities and relationships in the northern Shariaimplementing states of Nigeria, Somalia, and another five countries in the world attract the death penalty. In 71 countries and five entities, the punishment is imprisonment. ${ }^{1,7}$ According to chapter 21 articles 214 and 217 of the country's criminal code, same-sex sexual activity is a felony in Nigeria, and punishable by imprisonment of up to 14 years. ${ }^{1,6,7}$

Greater experiences of family rejection, a traumatic form of emotional abuse as a result of gender identity and sexual orientation, has been linked with poor mental health outcomes (attempted suicide, high levels of depression, and substance use problems among adolescents). ${ }^{8}$ One of the recognized coping mechanisms seen upon exposure to a stressful environment is alcohol and drug use aimed at numbing the pain experienced. This can lead to alcohol dependency and drug abuse, creating a situation whereby men will engage in risky sexual behavior. They may even commit criminal offences under the influence of these substances.

Globally, the number of new HIV infections and acquired immune deficiency syndrome (AIDS)-related deaths has been dropping over the years. An estimated 20\% reduction in the number of people newly infected with HIV and 24\% fewer deaths from the disease was observed between 2001 and 2011. ${ }^{5}$ In Nigeria, available reports indicate an increase in the number of people newly infected with HIV from an estimated 250,000 in 2005 to over 388,000 in 2012. Men who have sex with men (MSM) and their partners, according to the report, were responsible for $10 \%$ of all new infections that occurred in the country within that time period. ${ }^{9}$

Globally, the prevalence of HIV has been observed to be higher among MSM than in the general population in most countries. ${ }^{5}$ In Nigeria, $17.2 \%$ of MSM were living with HIV in 2010 compared with the national prevalence of $4.1 \%{ }^{10}$ This study examined the occurrence of human rights violations among MSM living in Lagos in 2012 before the same sex marriage prohibition bill was signed into law by the president of the Federal Republic of Nigeria.

\section{Materials and methods}

The study site was Lagos, a densely populated cosmopolitan city in south western Nigeria. A list of community centers frequented by MSM in Lagos State was collected from the Lagos State AIDS Control Agency. Only seven of the 20 local government areas (LGAs) in the state had community centers for MSM. The centers are usually rented apartments run by local MSM-led nongovernmental organizations. Their activities are sponsored by partners and donor agencies through grants, provision of behavioral communication materials, training, and capacity development of staff. The centers are not open to the general public. MSM go there to access services through referrals and by one-on-one introduction. Activities are carried out indoors; there are no banners or signpost advertising the venue or its activities. It is a close-knit setting; some of the staff manning the centers are females, but only MSM can access services at these centers.

\section{Selection of LGA for the study}

Three of the seven LGAs were selected through simple random sampling; each of the selected LGAs had only one 
community center, so all three were used. Advocacy visits were subsequently conducted to the three community centers, and the stakeholders and networks manning the centers were duly briefed on the study and its purpose. The benefit of the study was also highlighted, and verbal informed consent was given by the authorities manning the three centers.

Participants recruited for the study were men over 18 years of age who had had sexual relationships with members of the same sex and visited the community center for recreational activities or HIV prevention information and services between 9 am and $6 \mathrm{pm}$ from Monday to Saturday in August 2012. Heterosexuals who visited the community centers for whatever reason during the period of data collection were excluded from participation by staff and peers. Only MSM who agreed to participate in the study were given questionnaires to complete. Participation was voluntary and participants were assured that all information supplied would be anonymous and kept in a confidential manner.

The formula for calculating sample size in a crosssectional descriptive study was used based on the proportion of MSM reporting risky sexual behavior in the 2010 Integrated Biological and Behavioural Surveillance Survey $(25.5 \%) .{ }^{10}$ The significance level was set at 0.05 and a calculated minimum sample size of 291 was obtained, which was increased by $10 \%$ to 320 to allow for nonresponse.

\section{Selection of participants}

The sample size was divided equally among the three centers. The snowball sampling method was used to recruit 107 participants from each of the centers. The MSM operating the centers were recruited as the initial seeds, and were then asked to recruit peers who visit the centers. These next groups of respondents were similarly asked to identify peers, and this went on until the desired sample size was attained. None of the respondents received any form of incentive or reimbursement for participation in this research. All questionnaires were administered at the community centers. Three research assistants were recruited, trained, and paid a stipend to assist in the distribution and collection of the questionnaires in the field.

Ethical approval was obtained from the Lagos University Teaching Hospital health research and ethics committee (reference ADM/DCST/HREC/Vol. XVI/APP/454) to conduct the study, with verbal approval from respondents.

A semistructured pretested questionnaire was used to collect information on demographics, alcohol and drug use, HIV risk behavior, and experience of human rights violations. Aggression was described as unprovoked attacks, confrontation, and violent behavior as a result of sexual orientation. Alienation was described as a perceived feeling of isolation by family or friends from activities which they would have normally been involved in. The data analysis was done using Statistical Package for the Social Sciences version 20 software (IBM Corporation, Armonk, NY, USA) and presented as means and percentages. Only 291 questionnaires were analyzed because some of the respondents did not complete all items in the questionnaire.

Bivariate analysis was performed to test the relationship between dependent and independent variables at $P<0.05$. A logistic regression model was used to assess the relationship between the outcome variables, namely acts of aggression and sexual and physical abuse, and sociodemographic variables that were statistically significant on bivariate analysis with a $95 \%$ confidence interval and $P<0.05$.

\section{Results}

The study participants had a mean ( \pm standard deviation) age of $25.3 \pm 4.6$ years, close to two thirds $(59.1 \%)$ had at least a secondary school education, and $29.9 \%$ had post-secondary education. Two thirds $(66.0 \%)$ of the men were currently single and not in a steady relationship, while $19.6 \%$ were cohabiting or in a steady relationship and only $12.0 \%$ were married. Regarding sexual orientation/identity, $50.5 \%$ self-reported as gay, $47.8 \%$ as bisexual, and $1.7 \%$ as transgender (Table 1 ).

Alcohol use was quite common, with $56.7 \%$ of the MSM consuming alcohol; in this group, more than half (57.6\%) reported drinking alcohol to the point of intoxication. About a quarter $(25.8 \%)$ of the men smoked cigarettes. Only $11.1 \%$ of the men reported using hard drugs, ie, marijuana, amphetamines, and cocaine, and none reported using more than one type of hard drug or injecting drugs (Table 1).

Recreational activities include visiting hotspots (reported by $43.6 \%)$, partying $(38.8 \%)$, clubbing (35.7\%), watching movies (35.7\%), and surfing the Internet (39.2\%); 29.9\% of the men sought sexual partners at the community center, $21.0 \%$ from hotels/brothels, $39.5 \%$ at parties, $39.9 \%$ when they visited private homes, and $48.1 \%$ from bars/clubs.

One third $(33.0 \%)$ had disclosed that they had same sex relationships to either a family member/friend or both. Homosexual/transgender respondents were more likely to have made such a disclosure than bisexual respondents (51.3\% versus $15.8 \% ; P<0.001$, see Table 1$)$.

About a third of the men reported at least one act of human rights violation, ranging from aggression $35.7 \%$, alienation $29.9 \%$, discrimination in the workplace $8.2 \%$, eviction $2.1 \%$, or refusal of service $4.1 \%$. Another $20.3 \%$ reported at least 
Table I Sociodemographic characteristics

\begin{tabular}{|c|c|c|}
\hline Variable $(n=291)$ & Percent & Frequency \\
\hline \multicolumn{3}{|l|}{ Age, years } \\
\hline$<20$ & 13.7 & 40 \\
\hline $20-30$ & 76.3 & 222 \\
\hline$>30$ & 10.0 & 29 \\
\hline \multicolumn{3}{|l|}{ Mean $25.3 \pm 4.6$} \\
\hline \multicolumn{3}{|l|}{ Level of education } \\
\hline$<$ secondary school & 11.0 & 32 \\
\hline$\geq$ secondary school & 89.0 & 259 \\
\hline \multicolumn{3}{|l|}{ Marital status } \\
\hline Single, not in a steady relationship & 66.0 & 192 \\
\hline Single, in a steady relationship/cohabiting & 19.6 & 57 \\
\hline Married & 12.0 & 35 \\
\hline Divorced/separated & 2.4 & 7 \\
\hline \multicolumn{3}{|l|}{ Sexual identity } \\
\hline Homosexual/transgender & 52.2 & 152 \\
\hline Bisexual & 47.8 & 139 \\
\hline \multicolumn{3}{|l|}{ Disclosure to family/friend } \\
\hline Yes & 33.0 & 96 \\
\hline No & 67.0 & 195 \\
\hline Consumes alcohol & 56.7 & 165 \\
\hline Gets drunk $(n=165)$ & 57.6 & 95 \\
\hline Smokes cigarettes & 25.8 & 75 \\
\hline Uses hard drugs & II.I & 32 \\
\hline \multicolumn{3}{|l|}{ Type of hard drug $(n=32)$} \\
\hline Cocaine & 34.4 & 11 \\
\hline Ecstasy & 9.3 & 3 \\
\hline Marijuana & 56.3 & 18 \\
\hline \multicolumn{3}{|l|}{ Leisure activities* } \\
\hline Partying & 38.8 & 113 \\
\hline Clubbing & 35.7 & 104 \\
\hline Visiting hot spots with friends & 43.6 & 127 \\
\hline Watching television/movies & 35.7 & 104 \\
\hline Surfing the Internet & 39.2 & 114 \\
\hline \multicolumn{3}{|l|}{ Sourcing for sexual partners* } \\
\hline Clubs/bars & 48.1 & 140 \\
\hline Private homes & 39.9 & 116 \\
\hline Parties & 39.5 & 115 \\
\hline Community centers & 29.9 & 87 \\
\hline Hotels/brothels & 21.0 & 61 \\
\hline
\end{tabular}

Note: *Multiple responses.

one incident of violence, including rape by a man $16.8 \%$, verbal abuse $19.2 \%$, physical abuse $17.9 \%$, and psychological abuse $20.3 \%$ (Table 2 ).

On bivariate analysis, a higher proportion of MSM who were single and not in a steady relationship were found to report acts of aggression compared with those who were married/in a steady relationship $(P=0.003)$. Unmarried MSM did not report more instances of physical or sexual violence. A higher proportion of young MSM ( $<30$ years) and men with a low level of education reported experiencing acts of aggression, respectively ( $P=0.020$ and $P=0.029$; Table 3 ).
Table 2 Human rights abuses and experience of gender-based violence

\begin{tabular}{lll}
\hline Actions $(\mathbf{n = 2 9}$ I)* & Frequency & Percentage \\
\hline Aggression & 104 & 35.7 \\
Alienation & 87 & 29.9 \\
Discrimination in workplace & 24 & 8.2 \\
Eviction from residence & 6 & 2.1 \\
Refusal of service & 12 & 4.1 \\
Suspension from school/apprenticeship & 1 & 0.3 \\
Verbal abuse & 56 & 19.2 \\
Physical abuse & 52 & 17.9 \\
Psychological abuse & 59 & 20.3 \\
Sexual abuse & 49 & 16.8 \\
Endured at least one form of human & 104 & 35.7 \\
rights abuse & & \\
Victim of at least one act of violence & 59 & 20.3 \\
\hline
\end{tabular}

Note: *Multiple responses.

Homosexuals were more likely to report experiences of social oppression, ranging from acts of aggression $(P=0.002)$ to physical $(P=0.036)$ and sexual $(P=0.044)$ violence. Disclosure of sexual orientation was associated with acts of aggression $(P<0.001)$ and physical abuse $(P<0.001)$.

Alcohol consumption was associated with reports of physical $(P=0.020)$ and sexual $(P=0.001)$ violence. A higher proportion of MSM who solicited for sexual partners from brothels, clubs, and community centers reported instances of aggression ( $P=0.003, P=0.014$, and $P=0.003$, respectively).

The relationship between age and reported acts of aggression was not maintained in multivariate analysis. For the remaining factors, the direction of association remained consistent. MSM with less than a secondary school education were twice as likely to report acts of aggression (adjusted odds ratio $[\mathrm{AOR}] 2.6 ; P=0.019)$. Homosexual/transgender respondents were also twice as likely to report acts of aggression (AOR 1.9; $P=0.017$ ), as were unmarried MSM not in a steady relationship (AOR 2.3, $P=0.005$ ).

Men who consumed alcohol were three times as likely to report sexual abuse (AOR 3.4; $P=0.001$ ) and twice as likely to report physical abuse (AOR 2.3; $P=0.013$ ). Homosexual/ transgender men were twice as likely to report sexual (AOR 2.2; $P=0.021)$ and physical abuse (AOR 2.1; $P=0.022$ ).

\section{Discussion}

The respondents in this study were mostly young men under the age of 30 years with a fair level of education for a low income country. It has been observed that young MSM are especially vulnerable in this era of HIV infection. ${ }^{11}$ Decreasing or stable rates of infection have not been achieved in this group. Globally, less than $10 \%$ of MSM are estimated 
Table 3 Association between sociodemographic characteristics, human rights violation, and abuse

\begin{tabular}{|c|c|c|c|c|}
\hline & \multicolumn{2}{|l|}{ Aggression } & & \\
\hline & No frequency (\%) & Yes frequency (\%) & & \\
\hline \multicolumn{5}{|l|}{ Age (years) } \\
\hline$<30$ & $\mid 47$ (6I.3) & $93(38.8)$ & 240 & $\begin{array}{l}\chi^{2}=5.41 \\
P=0.020\end{array}$ \\
\hline \multirow[t]{2}{*}{$\geq 30$} & $40(78.4)$ & II (2I.6) & 51 & \\
\hline & 187 & 104 & 291 & \\
\hline \multicolumn{5}{|l|}{ Marital status } \\
\hline \multirow{2}{*}{$\begin{array}{l}\text { Never married and not } \\
\text { in a steady relationship }\end{array}$} & $112(58.3)$ & $80(4 \mid .7)$ & 192 & $\chi^{2}=8.63$ \\
\hline & & & & $P=0.003$ \\
\hline \multirow[t]{2}{*}{ Others } & $75(75.8)$ & $24(24.2)$ & 99 & AOR 2.3 \\
\hline & 187 & 104 & 291 & $P=0.005$ \\
\hline \multicolumn{5}{|l|}{ Level of education } \\
\hline \multirow[t]{2}{*}{$<$ secondary school } & $15(46.9)$ & $17(53.1)$ & 32 & $\chi^{2}=4.73$ \\
\hline & & & & $P=0.029$ \\
\hline \multirow[t]{2}{*}{$\geq$ secondary school } & $172(66.4)$ & $87(33.6)$ & 259 & AOR 2.6 \\
\hline & 187 & 104 & 291 & $P=0.019$ \\
\hline \multicolumn{5}{|l|}{ Orientation } \\
\hline \multirow[t]{2}{*}{ Homosexual/transgender } & $85(55.9)$ & $67(44.1)$ & 152 & $\chi^{2}=9.64$ \\
\hline & & & & $P=0.002$ \\
\hline \multirow[t]{3}{*}{ Bisexual } & $102(73.4)$ & $37(26.6)$ & 139 & AOR 1.9 \\
\hline & 187 & 104 & 291 & $P=0.017$ \\
\hline & Physical abuse & & & \\
\hline \multicolumn{5}{|l|}{ Orientation } \\
\hline \multirow[t]{2}{*}{ Homosexual/transgender } & $85(55.9)$ & $67(44.1)$ & 152 & $\chi^{2}=4.39$ \\
\hline & & & & $P=0.036$ \\
\hline \multirow[t]{2}{*}{ Bisexual } & $102(73.4)$ & $37(26.6)$ & 139 & AOR 2.I \\
\hline & 187 & 104 & 291 & $P=0.022$ \\
\hline \multicolumn{5}{|l|}{ Alcohol } \\
\hline \multirow[t]{2}{*}{ No } & III (88.I) & 15 (II.9) & 126 & $\chi^{2}=5.39$ \\
\hline & & & & $P=0.020$ \\
\hline \multirow[t]{3}{*}{ Yes } & $128(77.6)$ & $37(22.4)$ & 165 & AOR 2.3 \\
\hline & 239 & 52 & 291 & $P=0.013$ \\
\hline & Sexual abuse & & & \\
\hline \multicolumn{5}{|l|}{ Orientation } \\
\hline \multirow[t]{2}{*}{ Homosexual/transgender } & 120 (78.9) & $32(2 I . I)$ & 152 & $\chi^{2}=9.64$ \\
\hline & & & & $P=0.044$ \\
\hline \multirow[t]{2}{*}{ Bisexual } & $122(87.8)$ & $17(12.2)$ & 139 & AOR 2.2 \\
\hline & 242 & 49 & 291 & $P=0.021$ \\
\hline \multicolumn{5}{|l|}{ Alcohol } \\
\hline \multirow[t]{2}{*}{ No } & II5 (9I.3) & II (8.7) & 126 & $\chi^{2}=10.43$ \\
\hline & & & & $P=0.001$ \\
\hline \multirow[t]{2}{*}{ Yes } & $127(77.0)$ & $38(23.0)$ & 165 & AOR 3.4 \\
\hline & 242 & 49 & 291 & $P=0.00 \mathrm{I}$ \\
\hline
\end{tabular}

Abbreviation: AOR, adjusted odds ratio.

to have access to HIV prevention services at an individual level, within a social context, within communities, or from health service providers. ${ }^{12}$ Further, a high prevalence of HIV infection was recorded among people less than 30 years of age in the 2010 national seroprevalence study conducted among the general population in Nigeria. ${ }^{9}$

Bisexuality has been found to be common among African MSM. The proportion of the young people in this study who described themselves as bisexual is much higher than the $17 \%$ recorded in Cape Town. ${ }^{13}$ Bisexuality was described as an adaptation to escape the social stigma associated with gender orientation or identity by MSM in Senegal. ${ }^{14}$

Alcohol consumption was more common than tobacco use or substance abuse, and like the study conducted among MSM in Northern Thailand, alcohol use and substance abuse 
was not significantly associated with sexual orientation. ${ }^{15}$ In African countries where same sex relationships have been criminalized or where MSM experience social stigma, more and more MSM are turning to the Internet to meet their peers as well as to solicit for sexual partners. ${ }^{16}$

Studies carried out in various African countries have reported human rights violations among MSM. In Cape Town, almost a quarter of respondents in one study had been subjected to either blackmail, physical/sexual abuse, or denial of services. ${ }^{13}$ In Lesotho, about three quarters of MSM in a study reported having experienced beatings, rape, blackmail, or harassment as a result of their sexual orientation. ${ }^{17}$ Respondents in a multicountry study carried out in Malawi, Namibia, and Botswana mentioned violence as a threat to their life as MSM, with more than 40\% having been raped by men, beaten up, blackmailed, or denied health care. ${ }^{16}$ Experiences of MSM in this study with regard to this issue were similar, although sexual orientation was a predictor of social oppression.

Social stigma puts MSM at greater risk of developing mental health problems, thereby adding to the disease burden. In most sub-Saharan African countries, the expression of masculinity is that men should be strong and not display signs of weakness or vulnerability. This leads to poor health-seeking behavior by men, resulting in a low turnout for preventive, curative, and rehabilitative care until disease has progressed or complications arise resulting in premature death. ${ }^{18}$

An HIV prevention, care, and treatment program carried out in Senegal between 2004 and 2007 was able to achieve a reduction in individual risk-taking behavior (unprotected sex) among MSM. This can only be carried out in an environment free of violence, blackmail, and acts of discrimination. With the criminalization of same sex relationships in the same country, there was a substantial reduction in the provision of services by health workers and the uptake of these services. The majority of the targeted group went into hiding as a result of increased violence and discrimination. ${ }^{14}$ Similarly, a high proportion of MSM in other African countries reported being afraid to seek health care services because they had been victims of blackmail on the basis of their sexual orientation. ${ }^{19}$ Bisexual men in hiding will not access services from community centers and networks linked to MSM because of fear of exposure. At the same time, they are not adequately catered for in national programs, which focus more on women and children. They are therefore at the risk of being missed, excluded, or side-lined. ${ }^{19}$

\section{Limitations and conclusion}

Recruitment of MSM occurred at a community center which is most probably frequented by MSM from a particular network/LGA. Access to the study population would have been extremely difficult if the researchers did not actively engage the management team of the centers. The MSM operating the centers were the ones recruiting their peers into the study, which could have introduced some degree of selection and response bias. A nonprobability sampling method was used to recruit participants for the study, even though the LGAs where the centers were located were selected using a simple random sampling method.

This study was carried out among a subset of the key population in need of intervention in the HIV epidemic, and reveals that MSM in Lagos State have been victims of various acts of human rights violation and abuse. These could serve as structural barriers to access to services. There is an urgent need to document and quantify these happenings in all the states of the federation. It will also be necessary to investigate how human rights violations of MSM in Nigeria impacts on access to HIV care and prevention of transmission.

\section{Disclosure}

The authors report no conflicts of interest in this work.

\section{References}

1. World Health Organization, Pan American Health Organization. Health and freedom from discrimination. Health and human rights publication series. Washington, DC, USA: WHO Regional Office for the Americas; 2001. Available from: http://www.who.int/hhr/activities/q_and_a/ en/Health_and_Freedom_from_Discrimination_English_699KB.pdf. Accessed October 25, 2014.

2. Murray SO, Roscoe W, editors. Boy-Wives and Female Husbands. New York, NY USA: Palgrave Publishers, St Martin's Press; 1998.

3. Altman D, Aggleton P, Willams M, et al. Men who have sex with men. Lancet. 2012;380:439-445.

4. Joint United Nations Program on HIV/AIDS, World Health Organization. AIDS epidemic update 2005. Geneva, Switzerland: Joint United Nations Program on HIV/AIDS/World Health Organization; 2005. Available from: http://data.unaids.org/publications/irc-pub06/epi_update2005_ en.pdf. Accessed October 24, 2014.

5. Joint United Nations Program on HIV/AIDS. Global Report on the global AIDS epidemic 2012. Geneva, Switzerland: Joint United Nations Program on HIV/AIDS; 2012. Available from: http://www.unaids. org/en/media/unaids/contentassets/documents/epidemiology/2012/ gr2012/20121120_UNAIDS_Global_Report_2012_with_annexes_ en.pdf. Accessed October 24, 2014.

6. International Commission of Jurists and International Service for Human Rights. The application of international human rights law in relation to sexual orientation and gender identity. Available from: http://www. yogyakartaprinciple.org/principles_en.htm. Accessed September 13, 2013.

7. The International Lesbian, Gay, Bisexual, Trans and Intersex Association. Lesbian and gay rights in the world, May 2013. Available from: http:// www.ilga.org/statehomophobia. Accessed September 13, 2013. 
8. Ryan C, Huebner D, Rafael M, Diaz RM, Jorge Sanchez J. Family rejection as a predictor of negative health outcomes in White and Latino lesbian, gay, and bisexual young adults. Pediatrics. 2009;123: 346-355.

9. National Agency for Control of HIV/AIDS. Global AIDS Response Country progress report Nigeria. Abuja, Nigeria: Federal Government of Nigeria; 2012. Available from: http://www.unaids.org/en/ dataanalysis/knowyourresponse/countryprogressreports/2014co untries/NGA_narrative_report_2014.pdf. Accessed October 24 2014.

10. Federal Government of Nigeria. HIV Integrated Biological and Behavioural Surveillance Survey. Available from: http://www. popcouncil.org/uploads/pdfs/2011HIV_IBBSS2010.pdf. Abuja, Nigeria: Federal Ministry of Health; 2010.

11. Beck J, Santos G, Ayala G. Young men who have sex with men: health, access and HIV. Data from the 2012 Global Men's Health and Rights (GMHR) survey. A policy brief. Oakland, CA, USA: Global Forum on MSM and HIV; 2013. Available from: http://www.msmgf.org/files/ msmgf/Publications/MSMGF_YMSM_PolicyBrief.pdf. Accessed October 24, 2014.

12. Beyrer C. Global prevention of HIV infection for neglected populations: men who have sex with men. Clin Infect Dis. 2010;50 Suppl 3: S108-S113.
13. Baral S, Burrell E, Scheibe A, Brown B, Beyrer C, Bekker LG. HIV risk and associations of HIV infection among men who have sex with men in peri-urban Cape Town, South Africa. BMC Public Health. 2011;11:766-773.

14. Poteat T, Diouf D, Drame FM, et al. HIV risk among MSM in Senegal: a qualitative rapid assessment of the impact of enforcing laws that criminalize same sex practices. PLoS One. 2011;6:e28760.

15. Chariyalertsak S, Kosachunhanan N, Saokhieo P, et al. HIV incidence, risk factors, and motivation for biomedical intervention among gay, bisexual men, and transgender persons in Northern Thailand. PLoS One. 2011;6:e24295.

16. Baral S, Trapence G, Motimedi F, Umar E, Iipinge S, Dausab F. HIV prevalence, risks for HIV infection, and human rights among men who have sex with men (MSM) in Malawi, Namibia, and Botswana. PLoS One. 2009;4:e4997.

17. Baral S, Adams D, Lebona J, et al. A cross-sectional assessment of population demographics, HIV risks and human rights contexts among men who have sex with men in Lesotho. J Int AIDS Soc. 2011;14:36.

18. Williams DR. The health of men: structured inequalities and opportunities. Am J Public Health. 2003;93:724-731.

19. Fay H, Baral SD, Trapence G, et al. Stigma, health care access and HIV knowledge among men who have sex with men in Malawi, Namibia and Botswana. AID Behav. 2011;15:1088-1097.
HIV/AIDS - Research and Palliative Care

\section{Publish your work in this journal}

HIV/AIDS - Research and Palliative Care is an international, peerreviewed open-access journal focusing on advances in research in HIV, its clinical progression and management options including antivira treatment, palliative care and public healthcare policies to control viral spread. The journal welcomes original research, basic science,

\section{Dovepress}

clinical \& epidemiological studies, reviews \& evaluations, expert opinion \& commentary, case reports \& extended reports. The manuscript management system is completely online and includes a very quick and fair peer-review system. Visit http://www.dovepress.com/ testimonials.php to read real quotes from published authors. 